\title{
Effects Of Body Weight On Some House Works Efficacy And Some Physiological Parameters Of Females
}

\author{
Mohamed Zakaria Al-Etreby., Fawzy Ahmed Mohamed Ashour., Khaled \\ Ahmed Ezam*And Atef Mohamed Mosa Sharaf \\ Physiology Department, Al-Azhar And Al-Mansoura* Faculties Of Medicine
}

\begin{abstract}
In this work the effect of excess body weight on house works and some physiological parameters were conducted on twelve females' university students. The students were divided into a control (normal weight) group and experimental (overweight) group. The weakly cleaning of the living room was chosen as house work. A room was prepared as a living room with some furniture like tables, chairs, a sofa and cupboard in addition to a carpet on the ground and curtains on the walls. Observation of complexion, tremors, behavior reflecting boredom, level and time of performance as well as any complaint as tiredness, back pain, leg pain. Some physiological parameters as pulse, blood pressure, respiratory rate forced respiratory capacity and expiratory time were measured.

The results showed that overweight has passive effect on time and level of performance; also it affects the circulatory functions more than the respiratory functions. So house works are not considered as hard work and not sufficient to reduce body weight in overweight women. Also house works can be tolerated and there is no need to restrict activity to guard against respiratory distress
\end{abstract}

\section{Introduction}

Excess weight in females actually represents a multi-aspect problem. Beside the harmful health effects accompanying excess weight; it also has social and psychological effects (Friedman et al., 1995). Many housewives suffer from excess weight especially at the age of forty as a result of biological changes (Pronk et al., 2004). Some females believe that just physical activities either in house or office works are sufficient for preserving weight stability, avoiding many diseases and improving general health (Stunkard et al., 1996). Studies demonstrated that a most lazy subject can enjoy good health if he spends 30 minutes or more in daily physical activities. Steidl and Braton (1967) indicated that body weight directly affect physical performance and bearing the daily life burdens and that excess weight increase the complaining of feeling tired, back and joint pain as well as leg difficulties. Inspite of cultural progress, which was supposed to raise the individual awareness of health care and caring for beauty measures, rates of excess weight increased (Malnick and
Knobler., 2006) That's due to the excessive dependence on modern machines; unawareness of importance of sports practice and sedentary life (Maffeis et al., 1998).

The relation between body weight and work performance especially in the field of housework doesn't receive the enough care. So the aim of this work is to throw light on the effect of excess body weight on performance of housework and some physiological parameters in woman.

\section{Individual And Methods}

Twelve female university students were chosen .Their weight range between (60-99 kg), their age ranged between (18-22 years) and clinically free as regard cardiopulmonary diseases, diabetes and skeletal deformity.

Student with body weight range from $60 \mathrm{~kg}$ to $65 \mathrm{~kg}$ and height range from 160 $\mathrm{cm}$ to $165 \mathrm{~cm}$ were considered of normal weight while those with body weight range from $92 \mathrm{~kg}$ to $99 \mathrm{~kg}$ and height range 
from $160 \mathrm{~cm}$ to $165 \mathrm{~cm}$ were considered of overweight (Pekelis., 1987), so they were divide to two groups:-

Control group: 6 students with weight range $(60-65 \mathrm{~kg})$.

Excess weight group: 6 students with weight range (92-99 kg).

The weekly cleaning of the living room, considering it from the hard houseworks was chosen (Nickell \&Dorsey, 1976). A room was prepared as a living room with some furniture like tables, chairs, a sofa and cupboard in addition to a carpet on the ground and curtains on the walls.

The following parameters were determined at the beginning and the end of performance.

- Circulatory parameters: Pulse and blood pressure (using sphygmomanometer and stethoscope)

- Respiratory parameters: Respiratory rate, forced vital capacity and expiratory time (using spirometer)

- Time of performance (using stopwatch)

- Observation of complexion, tremors, behavior reflecting boredom and level of performance (Anoakly, 1976) as well as any complaint (tiredness, back pain, leg pain)

\section{Results}

Pulse rate showed an insignificant preperformance and a significant $(\mathrm{P}<$
0.001) postperformance increase in overweight group as compared to control normal weight group .Blood pressure showed an insignificant preperformance and a significant $\quad(\mathrm{P}<0.01)$ postperformance increase in overweight group as compared to control normal weight group (Table: 1).

The respiratory rate showed an insignificant preperformance decrease and postperformance increase in overweight group as compared to control normal weight group. The forced vital capacity showed an insignificant pre and postperformance increase in overweight group as compared to control normal weight group. The expiratory time showed an insignificant pre and postperformance increase in overweight group as compared to control normal weight group.(Table ,2).

The excess weight group showed some psycho-physiological changes in the form of tiredness $(66.6 \%)$, back pain (100\%), leg pain $(100 \%)$, tremors $(83 \%)$ and cyanosis $(50 \%)$. This group showed also some disturbances in performance in the form of slow movements (83\%), random intermittent hand movements $(66.6 \%)$ and periods of cessation (83\% .Table 3 )

The excess weight group showed a significant $(P<0.01)$ increase in time of performance and a significant $(\mathrm{P}<0.01)$ decrease in level of performance as compare to control group (Table 4)

Table (1): Circulatory changes in control and excess weight groups before and after
performance

\begin{tabular}{|c|c|c|c|c|c|c|c|}
\hline \multirow{2}{*}{\multicolumn{2}{|c|}{ Groups $(\mathrm{n}=6)$}} & \multicolumn{2}{|c|}{$\begin{array}{c}\text { Pulse } \\
(\text { Mean } \pm \text { SD) }\end{array}$} & \multicolumn{2}{|c|}{$\begin{array}{c}\text { Systolic B P } \\
\text { (Mean } \pm \text { SD) }\end{array}$} & \multicolumn{2}{|c|}{$\begin{array}{l}\text { Diastolic B P } \\
(\text { Mean } \pm \text { SD) }\end{array}$} \\
\hline & & Before & After & Before & After & Before & After \\
\hline I & Control group & $77.8 \pm 5.9$ & $96.7 \pm 6.1$ & $116.7 \pm 9.3$ & $122.2 \pm 8.3$ & $77 \pm 5.22$ & $79 \pm 4.22$ \\
\hline \multirow{2}{*}{ II } & \multirow{2}{*}{$\begin{array}{l}\text { Overweight } \\
\text { group }\end{array}$} & $84.2 \pm 9.0$ & $130.2 \pm 5.3$ & $124.8 \pm 6.6$ & $128.5 \pm 8.1$ & $81 \pm 5.8$ & $88 \pm 4.1$ \\
\hline & & insignificant & $\mathrm{P}<0.001$ & insignificant & $\mathrm{P}<0.01$ & insignificant & $\mathrm{P}<0.01$ \\
\hline
\end{tabular}


Mohamed Zakaria Al-Etreby et al

Table (2): Respiratory changes in control and excess weight groups before and after performance

\begin{tabular}{|l|l|l|l|l|l|l|l|}
\hline \multirow{2}{*}{ Groups (n=6) } & \multicolumn{2}{|c|}{$\begin{array}{c}\text { Respiratory rate } \\
(\text { Mean } \pm \text { SD) }\end{array}$} & \multicolumn{2}{c|}{$\begin{array}{r}\text { Forced vital capacity } \\
(\text { Mean } \pm \text { SD) }\end{array}$} & \multicolumn{2}{c|}{$\begin{array}{c}\text { Expiratory time } \\
\text { (Mean } \pm \text { SD) }\end{array}$} \\
\cline { 3 - 8 } & Before & After & Before & After & Before & After \\
\hline I & Control group & $17 \pm 1.4$ & $25.2 \pm 2.2$ & $89.8 \pm 6.2$ & $95.2 \pm 7.5$ & $7.1 \pm 1.2$ & $6.2 \pm 0.1$ \\
\hline \multirow{2}{*}{ II } & \multirow{2}{*}{ Overweight group } & $18.2 \pm 1.7$ & $28.5 \pm 4.8$ & $116.8 \pm 5.3$ & $121.8 \pm 6.2$ & $4.2 \pm 0.9$ & $5.7 \pm 0.9$ \\
\cline { 3 - 8 } & & \multicolumn{2}{|c|}{ insignificant } & \multicolumn{2}{|c|}{ insignificant } & \multicolumn{2}{|c|}{ insignificant } \\
\hline
\end{tabular}

Table (3): Psycho-physiological changes in excess weight group and its effects on performance

\begin{tabular}{|l|l|l|l|}
\hline Parameter & Symptom and signs & Frequency & Percentage \\
\hline \multirow{5}{*}{ Psycho-physiological } & Tiredness. & 4 & 66.6 \\
& Back pain. & 6 & 100 \\
& Leg pain. & 6 & 100 \\
& Tremors. & 5 & 83 \\
& & & \\
\hline \multirow{3}{*}{ Effects on performance } & Slowing in movements. & 5 & 83 \\
& Random intermittent hand movements. & 4 & 66.6 \\
& Periods of cessation. & 5 & 83 \\
\hline
\end{tabular}

Table (4): time and level of performance in control and excess weight groups

\begin{tabular}{|c|c|c|c|}
\hline \multicolumn{2}{|c|}{ Groups $(\mathrm{n}=6)$} & $\begin{array}{l}\text { Time of performance }(\mathrm{min}) \\
(\text { Mean } \pm \text { SD) }\end{array}$ & $\begin{array}{l}\text { Level of performance } \\
\quad(\text { Mean } \pm \text { SD) }\end{array}$ \\
\hline I & Control group & $57 \pm 3.22$ & $492.3 \pm 11.3$ \\
\hline \multirow{2}{*}{ II } & \multirow{2}{*}{ Overweight group } & $93 \pm 15.02$ & $395.7 \pm 26.0$ \\
\hline & & $\mathrm{P}<0.01$ & $\mathrm{P}<0.01$ \\
\hline
\end{tabular}

\section{Disscussion}

Body weight is an important factor affecting physical activity. Most people ignore the bad effects of overweight which is reflected on the individual behavior, as well as in-door and out-door performance (Ross et al. ,2001). Neglecting sports practice and sedentary life are important factors in overweight Prentice et al (1996).
The present study showed that the individuals of overweight group were suffering from subjective psycho physiological manifestations as boredom, tension, general fatigue, back aches and leg aches when practicing work. In addition, there were tremors and changes in complexion. Physiological measures showed significant 
increase in pulse rate and $\mathrm{ABP}$ as compared to control group .These changes may be attributed to the overweight which may be considered as a burden on the body systems , particularly the musculoskeletal and cardiovascular systems (Goldfield et al., 2007). This can be assured by the slow and intermittent movements of the hands during work performance in addition to stoppage for moments which was interpreted by the individuals as fatigue .This was reflected on the level of performance, in overweight group as compared to control group . Madsen et al., 1998, mentioned that fatigue led to decreased work ability accompanied by increased work mistakes and low level of performance .

The results showed a significant increase in time of performance in overweight group compared to control normal weight group which agrees with the results of Crandell et al., (1973) who attributed this to stoppage of movements , slow and random movements due to fatigue and boredom (José et al., 2007) .These results agrees also with Anderson et al., (1988) and Gannong( 2005) .

In the current study, individuals of the overweight group showed insignificant preperformance increase in pulse rate as compared with normal weight group which could be considered as a physiological response because of increased demand on the heart to pump an increased blood volume (Bray, 2004) .After work performance, there was a significant increase in pulse rate in both groups but it was more apparent in overweight group which may be due to sympathetic response to over activity during work (Mansi and Drolet, 1997). In spite of the marked increase of pulse rate in excess weight group it was still within the physiological range and may be due to the cumulative effect of both stress of work and over weight (Gannong, 2005)

Overweight group showed a non significant before performance increase in both systolic and diastolic blood pressure which is normal in overweight persons to insure good perfusion to the excess body mass (Caroline et al., 2002).Significant increase in both systolic and diastolic blood pressure after performance were found.
This could be explained by the positive inotropic effect of sympathetic stimulation (Guyton and hall ,2006). The increased blood pressure was more marked in excess weight group which indicates that the excess weight is an additional burden on the circulatory system to cover these excess weight needs of $\mathrm{O} 2$ and nutrients (Heiman et al., 1997).

As regards the respiratory rate both groups showed an insignificant postperformance increase which was proportional in both groups indicating that the excess weight had no additional effect on the respiratory system. So the increased respiratory rate is most probably due to the effect of work stress on the respiratory center (Diana et al., 2006)).

The forced vital capacity (FVC) as well as the expiratory time showed insignificant post performance increase in both groups indicating that both the work and the excess weight were not enough burdens to increase respiratory effort (Gillison et al., 2006). As the regulation of respiration is mainly metabolic and as the work led to insignificant changes in respiratory parameters this indicates that the house woks are not sufficient to reduce body weight in overweight women (Keim et al., 1990). It was noted that the effect of work was more apparent on the circulatory than the respiratory system which indicates that the house works is a light work and not a hard work . This is contradictory to Gross et al., (1973) and Nickel \& Dorsy (1979) who consider these works as sever works . This contradiction may be due to difference in methodology as their study was as survey subjective reports without measuring physiological parameters.

In this study it may be conclude that house works are not sever works, so there is no need to restrict activity to guard against respiratory distress or consider these works as an exercise that can be useful for weight reduction in overweight women.

\section{References}

1. Anderson A E, Dibble T, and Rynbergen $M$ (1988): Nutrition in health and disease $.17^{\text {th }}$ ed Publishing Library of Congress pp:316-482.

2. Anoakly N (1976): The sociology of house work. New York,Random House, 29-41. 
3. Bray G A (2004): Medical Consequences of Obesity. J. Clin. Endocrinol. Metab. 89: 2583-2589

4. Caroline MA, Caroline M G, Craig W Z. Rogers C D and Gordon L J (2002): Body mass index and physical function in older women . Obes Res 10:740-747

5. Diana K, Rebecca, Suzanne B, Lucy O, Marcus R, Michael W, Cyrus $\mathrm{C}$ and Avan A S(2006): Developmental origins of midlife physical performance: evidence from a British birth cohort. American Journal of Epidemiology 164(2):110-121

6. -Friedman M A., Wilfley D E., Pike K M and Rodin J (1995): The relationship between weight and psychological functioning among women. Obes. Res., 3 :57-62

7. Ganong WF (2005): Review of medical physiology. $22^{\text {st }}$ edition. Lang and McGraw-Hill

8. Gillison F, Standage M, Skevington S (2006). Relationships among adolescents' weight perceptions, exercise goals, exercise motivation, quality of life and leisure-time exercise behavior: a self-determination theory approach. Health Educ. Res., 21: 836-847

9. Goldfield G S, Mallory R, Parker T, Cunningham T, Legg C, Lumb A., Parker K, Prud'homme D, Adamo K B. (2007). Effects of Modifying Physical Activity and Sedentary Behavior on Psychosocial Adjustment in Overweight/Obese Children. J Pediatr Psychol 32: 783-793

10. Gross I H, Crandall $\mathbf{E} W$ and Knoll (1973):Management of modern family Copyright (C) Meredith Corporation USA p 428-475.

11. Guyton AC and Hall JE (2006): Textbook medical physiology $11^{\text {th }}$ edition Elsevier Saunders Company. McGraw-Hill

12. Heiman M l, Ahina R S,Graft $L$ S and Flier J S( 1997): Leptin inhibition of hypothalamic-pituitary-adrenal axes in response to stress. Endocrinol 63(4):32737.

13. José A, Casajús M T, Leiva A , Villarroya A , Legaz L A ( 2007): Physical Performance and School Physical Education in Overweight Children . Annals of Nutrition and Metabolism 51:288-296.
14. Keim N L, Barbieri $\mathbf{T} \mathbf{F}$, Van L, Anderson B L (1990): Energy expenditure and physical performance in overweight women: response to training with and without caloric restriction. Metabolism. 39(6): 651-8

15. Madsen K L, Adams W C and Van-Loan M D (1998): The effect of performing physical activity on the exerted effort. Med Sci Sport Excer 30(1):114-124.

16. Maffeis $\mathbf{J} \mathbf{A}$, Talamini $\mathbf{G}$ and Tato $\mathbf{L}$ (1998): Influence of diet, physical activity and parents obesity on children's adiposity: a four year longitudinal study. Int $\mathrm{J}$ Obes_Relat-Metab- Disord 22:58-64.

17. Malnick SDH, Knobler H (2006). The medical complications of obesity. QJM 99: 565-579

18. Mansi J A and Drolet C ( 1997):Chronic stress induced sensitization of sympathetic nervous system. Am J Physiol 272 (6) :813820.

19. Nickell P and Dorsey J M ( 1976 ): Management in family living $.5^{\text {th }}$ ed New York 242-261.

20. Pekelis N (1987): Realize your potential . Pbl . Mir 130- 147.

21. Prentice A M , Goldberg $\mathbf{G}$, Murgatroyd P R and Cole T J ( 1996 ) : Physical activity and obesity : Problem in correcting expenditure for body size . Int-JObes-Relat-Metab-Disord 20 (7):88-91

22. Pronk P, Martinson B, Kessler R C, Beck A L, Simon G E, Wang P (2004): The Association Between Work Performance and Physical Activity, Cardiorespiratory Fitness, and Obesity. Journal of Occupational \& Environmental Med, 46(1):19-25.

23. Ross Robert Janssen Ian (2001): Physical activity, total and regional obesity: doseresponse considerations. Medicine \& Science in Sports \& Exercise. 33(6) :S521S527

24. Steidle R E and Bratton E C ( 1976): work in the home .New York : John Wiley \& Sons PP 120-129

25. Stunkard A, Foch $\mathbf{T}$ and Hrubic $\mathbf{Z}$ (1996): A twin study of human obesity JAMA., 25 : 51-54. 
تأثير وزن الجسم على كفاءة أداء بعض الأعمـال المنزلية وبعض القياسات

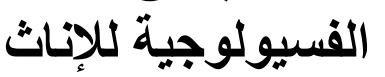

محمد زكريا الإتربى -- فوزى أحمد عاثور - خالد احمد عظام *-عاطف محمد

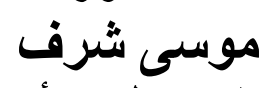

قسمى الفسيولوجيا- كليتي طب الأزهر وطب المنصورة:

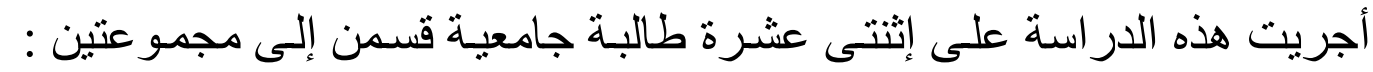

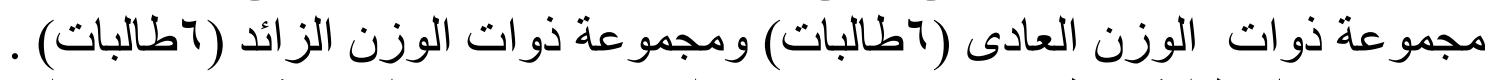

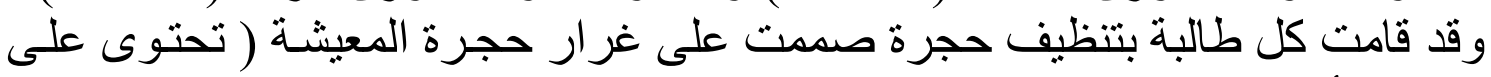

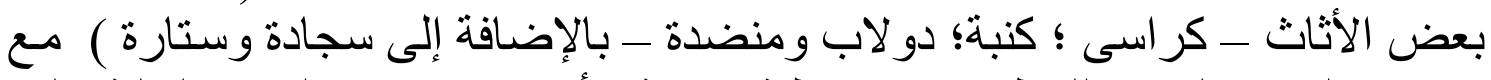

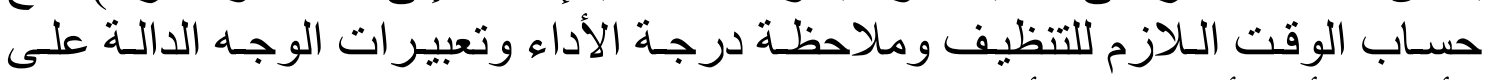

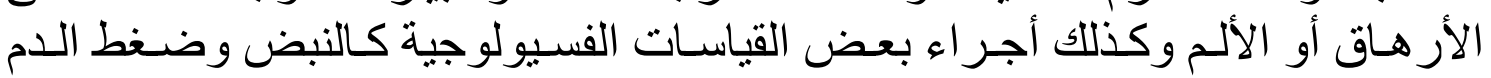

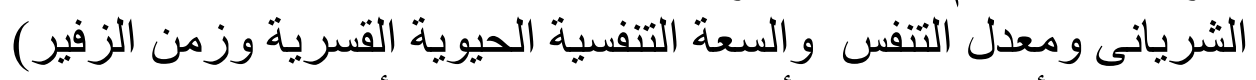

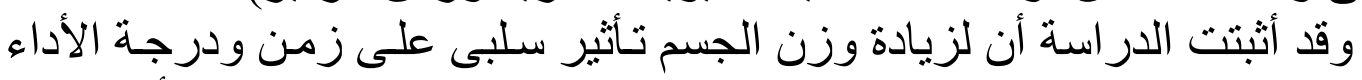

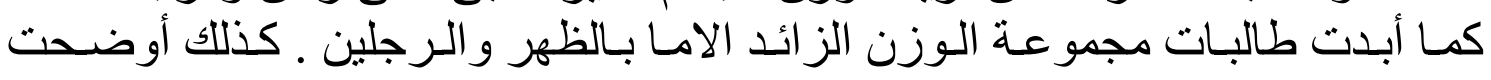

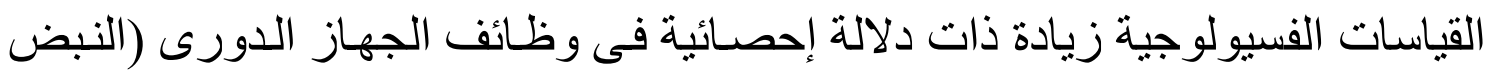

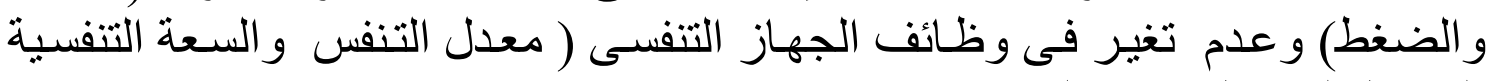

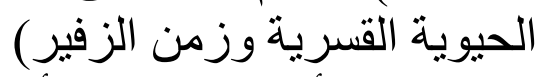

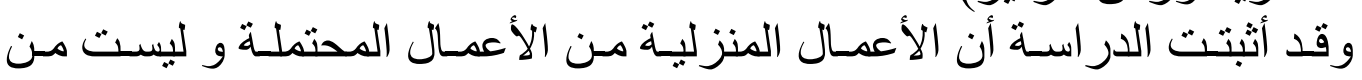

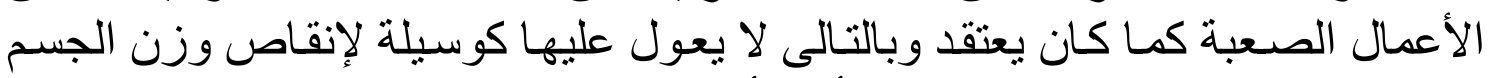

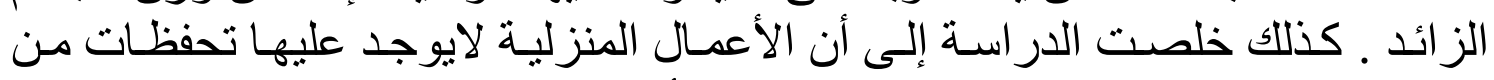

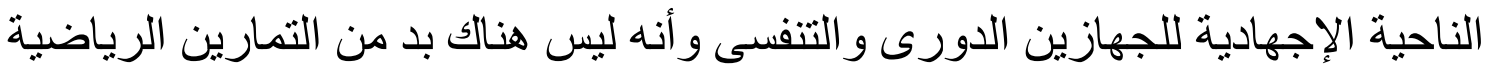
كوسيلة لإنقاص وزن الإدة الجسم الزائد 